\title{
Do Círculo de Eranos à construção do simbólico, em Carl Gustav Jung
}

\author{
Amauri Carlos Ferreira ${ }^{a}$ \\ Luiz Henrique Lemos Silveira ${ }^{b^{*}}$ \\ a Pontifícia Universidade Católica de Minas Gerais, Instituto de Ciências Humanas e Filosofia. Belo Horizonte, MG, Brasil \\ ${ }^{b}$ Faculdade Pitágoras. Teixeira de Freitas, BA, Brasil
}

Resumo: $O$ artigo discute a origem e a extensão do Círculo de Eranos e sua importância na compreensão do simbólico, estabelecendo a compreensão da construção do simbólico como tentativa de união entre Oriente e Ocidente em C. G. Jung.

Palavras-chave: Eranos, simbólico, arquétipo, Jung.

\section{Introdução}

Há uma infinidade de definições de cultura; tantas são elas que não se torna necessário trazer outras à superfície, de modo a se compreender que o ser humano como animal simbólico constrói e reconstrói seu ethos ${ }^{1}$ de forma variada, visando a seu pertencimento no mundo.

Ao atribuir sentido aos objetos que tocam a sensibilidade do ser humano - que cultiva relações com o mundo, consigo mesmo e com o outro - surge a necessidade de construção de símbolos para a definição de cultura, definições estas que abarcam o campo do conhecimento humano. Convém saber, digamos de forma fundamental, que boa parte das definições que compõem o imaginário ocidental e oriental trata do simbólico nas culturas. Autores, no geral, nem sempre atentam para a contribuição de um movimento pouco estudado - o Círculo de Eranos - o qual exerceu uma importância decisiva no modo de percepção deste simbólico.

Diversos autores no século XX, em várias áreas do conhecimento humano, são lidos e repetidos ad nauseam, sem ao menos mencionar a existência de Eranos; em certos casos, é total o desconhecimento deste Círculo e de sua relevância. No Brasil, particularmente nas Ciências Humanas e Sociais, nos estudos religiosos e na psicologia analítica de Jung, este conhecimento é quase inexistente. Cabe apontar, aqui, para o trabalho pioneiro de José Carlos de Paula Carvalho, com o Centro de Estudos de Antropologia do Imaginário, Culturanálise de Grupos e Educação; também com os estudos na área de antropologia de Danielle Rocha Pitta, com o Núcleo Interdisciplinar de Estudos do

* Autor correspondente: mitologf@uol.com.br

1 Ethos é uma palavra grega que significa casa, morada, lugar, lugar do ser no mundo. Esta morada não está pronta. Ela está sempre em construção. Em seu sentido original, ethos indica abrigo de animais, do qual derivará o termo moderno etologia: estudo do comportamento de animais. Remete também à ideia de costumes e, ao dizer do ser humano, assume o sentido de morada, casa, mais que abrigo, lugar que se tornou habitável. Compreender-se-á o homem como animal simbólico, como Ernest Cassirer (1994) - um dos participantes de Eranos - definia o homem como um ser simbólico mais que um ser racional. É nesta construção e reconstrução do ethos pelo simbólico que as formas de criação do mito, linguagem, ciência e arte tornam-se símbolos para a compreensão do ser humano.
Imaginário UFPE (Universidade Federal de Pernambuco), bem como as pesquisas de Dênis Domeneghetti Badia.

$\mathrm{Na}$ área de Ciências da Religião no Brasil, na qual o simbólico religioso é crucial, e os estudos, em sua maioria, são de natureza interdisciplinar, encontramos em alguns autores como Mircea Eliade, Rudolfo Otto, K. Kerényi, E. Cassirer, G. Bachelard, G. Dumezil, M. Buber, G. Duran, entre outros investigados nesta área, poucos e incipientes trabalhos relacionados a Eranos, até o ano de 2013, vinculados à psicologia analítica de C. G. Jung. Destes trabalhos, destaca-se o livro sobre o Simbolismo do Herói - uma abordagem sobre a Ciência do Imaginário, resultado de dissertação de mestrado², defendida na PUC Minas, em 2011.

Ao redigirmos este artigo para evidenciar a participação de Jung neste movimento, no que tange às suas palestras sobre a problemática do simbólico, deparamo-nos com a necessidade de dedicar uma parte a Eranos. Tal escolha deve-se à ausência de estudos sobre o Círculo e também à importância do mesmo para estudos que investigam o simbólico - compreendido como uma das formas de expressão do imaginário e uma tentativa de ser o elemento de mediação entre o Oriente e o Ocidente. Ao mesmo tempo, ocorreu-nos despertar de forma introdutória, para investigações futuras em estudantes e pesquisadores, a influência que este movimento proporcionou a autores estudados em nosso país, de formas disciplinares e interdisciplinares.

Neste sentido, compreender o simbólico em Eranos, partindo de C. G. Jung, vem a ser o objetivo precípuo deste artigo. De forma introdutória aponta-se, na primeira parte, para a origem e extensão deste círculo e sua importância no que se refere aos estudos sobre o simbólico na construção do imaginário.

\section{Origem e Extensão do Círculo de Eranos: a importância do simbólico}

O estudo sobre o imaginário, e o simbólico nele compreendido, tem sua origem no século XX. Diversos

\footnotetext{
2 Esta dissertação de Solange Missagia de Mattos foi revisada e publicada em 2013, sob o título $O$ simbolismo do herói - uma abordagem sobre a Ciência do Imaginário.
} 
autores e precursores destes estudos buscaram proporcionar um maior entendimento do ser humano, fosse em nível político, antropológico, espiritual, social etc. Muitos desses autores pertenceram a círculos de formação diferenciada, antecipando o movimento epistêmico interdisciplinar da segunda metade do século XX, o qual levou Piaget a afirmar (nos anos 1960) que o futuro pertenceria às pesquisas interdisciplinares.

Segundo Piaget, não temos mais que dividir a realidade em compartimentos impermeáveis ou plataformas superpostas correspondentes às fronteiras aparentes de nossas disciplinas científicas; pelo contrário, vimo-nos compelidos a buscar interações e mecanismos comuns. (Piaget, citado por Santomé, 1998, p. 51)

Talvez no interesse e nas pesquisas sobre o simbólico, numa tentativa de compreender a formação dos símbolos no ser humano e, ao mesmo tempo, numa tentativa de sair da concepção positivista que imperava na época, tenha ocorrido, nos anos de 1930 do século XX, a necessidade da fundação do círculo de Eranos. O Círculo de Eranos agregou, de forma interdisciplinar, autores de diversas áreas do saber humano. Sua fundadora, Olga Froebe-Kapteyn (1881-1962), demonstrava interesse pela filosofia esotérica e pela teosofia. Este interesse pelo Oriente a levou a propor uma correlação entre o Ocidente e o Oriente. Para Araújo e Baptista (2003), em Eranos,

a reflexão iniciada nos anos 30 procura sintetizar e harmonizar, no quadro de um fecundo e fecundante diálogo entre disciplinas e a partir da análise comparativo-contrastiva de práticas e procedimentos simbólicos, teorias e métodos de inspiração antropológica, filosófica, sociológica, histórica, psicológica e literária. (Araújo \& Baptista, 2003, p. 13)

Pode-se afirmar que os pesquisadores de Eranos eram influenciados por uma tendência de estudo do simbolismo, no qual se buscava um conhecimento gnóstico, o que se explicitava por uma tentativa de captação, não do sentido racional e objetivo das experiências, mas do nível mais profundo das experiências vividas.

As discussões do Círculo de Eranos - surgido em 1933 - perduram até a atualidade e são marcadas pela luta contra o espírito racional como forma de expressão de compensar a unilateralidade da razão. Mediante pesquisas interdisciplinares, seu intuito visa a aproximar a relação da cultura oriental e ocidental, de forma a compreendê-las num elo que demarca o ser humano quanto ao simbólico.

O nome de Eranos foi sugestão de Otto; em grego, Eranos significa comida em comum, troca de alimentos, pelos gregos, sem a presença de um anfitrião (Ortiz-Osés, 1994) ${ }^{3}$. Bernardini (2011) traz para seu conceito a possibili-

3 Pode-se dizer que Otto foi importante para Eranos não somente pela sugestão do nome, mas também por ele, anteriormente a Eranos, ter propiciado uma discussão filosófico-antropológica, em distintas obras, entre dade de remontá-la aos vocábulos gregos eroté e eorté, que indicam: serviço divino, sacrifício, festa religiosa, solenidade, a festa sacrificial. De tal sorte, a palavra Eranos pode indicar elementos constitutivos das duas culturas circunscritas a perspectivas compreendidas mediante o simbólico religioso.

Nesta mesma direção, mas com significado diferente, o mitólogo K. Kerényi, no intuito de definir a palavra Eranos, apropria-se do significado original do termo, que aparece pela primeira vez no mito grego da Odisséia de Homero, como referência a um "núcleo espiritual" em que os participantes tivessem liberdade e espontaneidade de expressão por meio da arte, de textos que retratassem a essência do ser humano (Eranos Foundation, n.d.).

Eranos reflete uma posição da cultura do "animismo", na qual a alma é vista como psique e mediadora entre espírito (ruah, pneuma) e corpo (matéria, hyle), visão esta que sustenta a concepção de Eranos, ou seja, a arquetipologia ${ }^{4}$ simbólica. A busca de Eranos faz-se pela complexio oppositorum (complexo dos opostos), uma união dos opostos. (Ortiz-Osés, 1994).

De posse do nome Eranos e o simbólico ali debatido nos encontros, um dos temas comuns e cruciais para os estudos sobre o imaginário e para a compreensão da psique humana é o mito. Esta categoria pertencente à primeira fase do círculo (de 1933 a 1946) é considerada a fase da mitologia comparada.

Deste modo, de acordo com Carvalho (1998), no artigo intitulado "El círculo de Eranos - uma hermenêutica simbólica del sentido", Ortiz-Osés aponta que o Círculo de Eranos se encerra em 1988, no qual se desenvolveram em três etapas os estudos de Eranos. A primeira, de 1933 a 1946, fase da mitologia comparada; de 1947 a 1971, fase da Antropologia Cultural, e a fase da "Hermenêutica Simbólica" ou "Antropologia Hermenêutica", que ocorreu de 1972 a 1988. No entanto, no site oficial de Eranos, este teve continuidade após 1988, havendo ainda mais quatro fases: Fase do Projeto I Ching (1989-2000), Fase do Declínio (2002-2005), Fase do Reinício I (2006-2009) e Fase de Reinício II (2010) (Eranos Foundation, n.d.).

\footnotetext{
o Ocidente (da mística cristã) e o Oriente (do hinduísmo). Deste modo, Otto é considerado padrinho de Eranos, nunca tendo, todavia, proferido nenhuma palestra devido a seu falecimento (Ortiz-Osés, 1994).

4 Esta arquetipologia simbólica a que André Ortis-Osés se refere está relacionada aos pares antitéticos em sua potência cultural. Uma busca de conjunção entre Oriente e Ocidente, mito e razão, diferença e identidade. Nesta arquetipologia presente no livro, encontram-se as chaves simbólicas de nossa cultura. Sua reflexão se volta para o matriarcalismo, patriarcalismo, fratriarcalismo - nos quais está presente a experiência arquetípica. Esta ideia está presente em Eranos, a partir de estudos sobre arquétipos. No livro Arquetipos y símbolos colectivos, em sua apresentação sobre Eranos, Andre Ortiz-Osés explica a importância da inspiração junguiana do Círculo, e de que forma a presença do simbolismo é central. Abre perspectivas para se perceber que a questão da imaginação simbólica em Eranos é relacional. O autor aponta para o simbolismo como um ecumenismo cultural. Gilbert Durand desenvolve este tema em suas estruturas antropológicas do imaginário, trazendo a questão da arquetipologia geral, "que descreve a imaginação criadora em seus regimes, estruturas e lógicas diferenciadas" (Barreto, 2008, pp. 35-36).
} 
Desta maneira, em nível de descrição histórica, Eranos se inicia com a fase denominada de mitologia comparada, de 1933 a 1946, publicada em 14 volumes, e que se destaca pela discussão da relação entre o pensamento ocidental e o oriental. De acordo com Carvalho (1998),

Essa fase da mitologia comparada chega a três conclusões básicas: 1- o domínio do "mythos" e do mítico configura-se como domínio de acesso do "inconsciente coletivo" à consciência, sendo, portanto, o domínio dos arquétipos do inconsciente coletivo ou da "Sombra" (fundamentalmente da "sombra coletiva" do Ocidente); 2- o inconsciente coletivo do homem ocidental cristão, de raízes greco-judaicas e da cultura indo-européia é configurado pelo "Oriente", seja o pagão, seja o pré-indo-europeu; 3- a importância de se descobrir e de se recuperar, trabalhando-o, o "homem arcaico', (o "primitivo" nos extratos profundos da psyche) como "paleo-psyche" (Solié), ou seja, o que nos é mais estranho e alheio (alteridades - Outro), assim o judeu no cristão, o primitivo no civilizado, o negro e o amarelo no branco etc. Dessa etapa participaram ativamente: Jung, Zimmer, Kerényi, Layard, Bernouilli, Rahner, Radin, Jensen, Benz, Buber, Pettazzoni, Buonaiutti, Przyluski, Piccard, Masson-Oursel, Leisegang, W. Otto, Schrödinger, Needham. (p. 24)

De 1947 a 1971, na fase da "Antropologia Cultural" publicaram-se 25 volumes, nos quais as discussões em Eranos se voltavam à imagem do homem, devido às barbaridades da guerra que muito comoveram a sociedade. Para Carvalho (1998)

A fase da antropologia cultural chega a quatro conclusões básicas: 1 . a necessidade de se repensar e de reconstruir a "imago homine"; 2. o homem como produtor e mediador das divisões sócio-culturais e psico-biológicas e sua responsabilidade ético-política e educativa, por exemplo, nas estratégias dos pré-conceitos; 3. a importância da mediação simbólica na constituição instaurativa das práticas sociais e as relações dos processos simbólicos com as dinâmicas organizacionais e educativas; 4 . A cultura como instrumento de reconstrução da unidade dispersa (o "Unus Mundus e o "Homo Unus") em direção a um ecumenismo de teor psico-cósmico e espiritual. . . . Participaram ativamente, não só os convivas anteriores, mas agora Neumann, Campbell, Van der Leeuw, Wilhelm, Scholem, Corbin, Eliade, Durand, Hillman, Radin, Jensen, Buytendijk, Plessner, Knoll, Suzuki, Benz, Tillich, Read, Zuckerkandl, Daniélou, Izutzu, Quispel, Von Uexküll, Huyghe, Servier, Holton. (p. 24)

Entre os anos 1972 a 1988, fase denominada de "Hermenêutica Simbólica" ou "Antropologia Hermenêutica", o foco se projetou na "mitologia hermenêutica"; aborda as atitudes arquetípicas diante do Sagrado, por meio de estudos dos arquétipos, mitos e símbolos.

A fase da hermenêutica simbólica chega a conclusões de alto valor não só teórico, mas heurístico. 1. Elaborase uma filosofia da cultura, que veremos presente, por exemplo, na Escola de Grenoble (o "novo espírito antropológico", NEA); 2. Essa filosofia da cultura centra-se no simbolismo-mediação e na hermenêutica do homo religiosus; ... São aqui ativos: Durand, Eliade, Hillman, Miller, Von Franz, Porket, Zahan, Fairvre, Brun, Guiomar, Ortiz-Osés. (Carvalho, 1998, pp. 25-26)

Nos anos de 1989 a 2000, a fase recebeu a denominação de Projeto I Ching, as atividades de Eranos voltando-se para as traduções e interpretações do Oráculo chinês do I Ching. Posteriormente, de 2002 a 2005, ocorre o período de declínio, em virtude da falta de organização e de sérios problemas financeiros; devido a tais fatores, não pôde apresentar nenhum projeto interessante. Mais à frente, graças ao interesse da cidade de Ascona e do governo de Cantone Ticino, Eranos se reestruturou e resolveu suas pendências financeiras (Eranos Foundation, n.d.).

De 2006 a 2009, Fase do Reinício, Eranos, por influência da fundação Oriente-Ocidente, e sob a presidência de John Van Praag desde 2005, elaborou um plano de negócio cujos objetivos foram de melhoria na Casa Eranos e Casa Gabriela, incentivo a contatos com parceiros importantes de pesquisas e reuniões anuais, retomadas com a publicação do Anuário n. 69. Por fim, em 2010, Fase do Reinício II, os membros remanescentes elegeram um novo presidente e secretário-geral, que prepararam um conjunto de regras para acesso aos documentos de Eranos, tendo reforçado os laços com parceiros acadêmicos da Fundação (Eranos Foundation, n.d.).

Nesta mesma direção, pode-se observar que, independentemente dessas fases que marcam focos diferentes de estudo, o objetivo principal de Eranos sempre foi o de compensar a unilateralidade do racionalismo pela abordagem do simbólico. Tal abordagem levou Ernest Cassirer, após suas reflexões, a corrigir e ampliar a definição clássica de homem, como animal racional, para um ser simbólico. O próprio autor reconhece que a expressão clássica não perdeu sua força, uma vez que

a racionalidade é um traço inerente a todas as atividades humanas. . . A razão é um termo muito inadequado para compreender as formas da vida cultural do homem em toda a sua riqueza e variedade. Mas todas essas formas são formas simbólicas. (Cassirer, 1994, pp. 49-50)

Assim, o Círculo de Eranos configura-se a partir de um grupo interdisciplinar, de importantes personagens internacionais, surgido em 1933 e perdurando até os dias atuais, e que busca compreender essas formas simbólicas. 
Segundo Bernardini (2011), Eranos teve grande influência sobre Jung, tendo percebido que suas pesquisas estavam em consonância com outras áreas do conhecimento. Bernardini relata que

Olga Fröbe-Kapteyn descreve nestes termos a importância da psicologia complexa em Eranos: A obra de C. G. Jung, ainda que nunca especialmente enfatizada, representa a força sintética no coração de Eranos. Essa obra, pode-se dizer sorrateira, invisivelmente uniu, deste modo, a todos e incorporou o significado mais profundo desta convenção. Ela estabelece uma rede de relações entre os diferentes âmbitos de pesquisa, entre outros oradores e entre todos os participantes ali reunidos, estivessem cônscios ou não disso. . . . Eranos . . . é a primeira e a única plataforma que coloca a psicologia representada por C. G. Jung em contato direto com muitos outros campos de pesquisa e com os maiores especialistas europeus .... Muitos dentre estes especialistas consideram Eranos como o seu lugar de encontro e têm descoberto como seus trabalhos estão totalmente interligados (uma descoberta dos próprios especialistas!). Muitos dos maiores cientistas especialistas europeus estabeleceram contato com a obra de C. G. Jung pela primeira vez no âmbito da convenção de Eranos ou através dos anais de Eranos. Este é um dos aspectos mais importantes de Eranos: o fato de que o ensinamento de Jung estivesse estabelecendo uma relação com diferentes âmbitos de pesquisa, através de seus próprios expoentes de destaque. A postura destes últimos diante de seu próprio trabalho começa a mudar, coisa que foi possível notar desde a primeira convenção. Começaram a perceber como os respectivos âmbitos de pesquisa, que até então pareciam isolados e absolutamente especializados, estavam na realidade ligados uns com os outros e, especialmente, com a mais jovem das ciências, a tal psicologia. (pp. 78-79. N.T)

Percebe-se, pois, Eranos, como um lugar propício para discussão de temas e autores que conduziam suas pesquisas em direção ao simbólico - discussões estas, nas quais foi possível a Jung dialogar com autores como Otto, Eliade e Zimmer.

Rudolf Otto teve grande influência em Eranos, no seu livro já anteriormente publicado, Das Heilige O Sagrado (2007), no qual enfatiza o estudo do aspecto ambíguo do sagrado-religioso, cujas características são: a racional e a irracional; fascinante e tremendo, do aspecto numinoso. Cabe salientar que Otto também se sobrepôs como figura importante na criação de Eranos, uma vez que ele já propiciara a discussão filosófico-antropológica em distintas obras entre o Ocidente (da mística cristã) e o Oriente (do hinduísmo) (Ortiz-Osés, 1994).

Nesta direção observa-se que era inevitável que, em Eranos, a obra de Otto estivesse em discussão, principalmente quanto à ideia do numinoso e ao aspecto sui generis que permeava tanto as pesquisas de Otto quanto as de Jung. Porém, faz-se mister desde já esclarecer as diferenças entre Otto e Jung, com relação ao entendimento do numinoso: Otto faz menção à ideia do numinoso a partir da especificidade da religião, ou seja, ele faz uma análise do numinoso, dos aspectos sui generis da religião e uma diferenciação dos aspectos racionais e irracionais partindo da especificidade da religião. Já Jung entende também o numinoso como aspecto sui generis da religião, no entanto, partindo de uma análise psicológica de sua concepção de religião.

Nesse sentido, pode-se observar que a ideia de numinoso no livro "O Sagrado" (Otto, 2007), tornou-se central no entendimento de Jung acerca da religião e, por outro lado, as abordagens dos dois autores ostentam enfoques diferentes, já que Otto busca uma compreensão do irracional a partir da especificidade da religião, enquanto Jung enfoca o aspecto do irracional - o efeito do numinoso - numa perspectiva psicológica, qual seja, a experiência numinosa como uma manifestação psicológica ou arquetípica durante as experiências religiosas do indivíduo. Jung aborda a religião e as experiências religiosas como experiências psíquicas reais, ou seja, como a experiência psíquica dos arquétipos, que possui característica numinosa, constituinte das religiões e presente em diversas experiências da humanidade. Deste modo, Jung entende que a constituição das religiões surja das experiências humanas.

Portanto, o entendimento de Jung identifica-se com o de Otto acerca de conceitos importantes como o numinoso, e o aspecto sui generis da religião como fator irracional e psicológico da experiência humana (Mackenna, 1999).

Nesta mesma direção, pode-se afirmar que o Círculo de Eranos marca a especificidade não somente dos pensamentos de Otto em relação a Jung, mas também em Eliade, uma vez que ambos buscavam o elemento irracional do ser humano, compreendendo as experiências da psique não apenas como vivências pessoais, mas também como pertencentes a um estrato coletivo próprio da psique humana, subjacente aos mitos e a todo o simbolismo religioso tradicional.

Assim, tanto Jung quanto Eliade ${ }^{5}$ afirmaram que a base da religião está no próprio homem, no sentido de que a psique humana está predisposta a manifestar pensamentos e comportamentos religiosos; o homem, portanto, seria religioso por sua própria natureza; seria um homo religiosus (Cavalcanti, 1998).

Neste mesmo enfoque de Eranos, ao ter proporcionado a Jung dialogar com outros autores, é possível perceber que Jung se identifica com o pensamento de Zimmer quando este propõe a necessidade de o Ocidente voltar-se

\footnotetext{
5 Apesar de as pesquisas de Eliade serem de outro viés - o da história das religiões - é possível apontar que há aproximações entre Jung e Eliade no que tange ao conteúdo arquetípico, em que os mitos e as religiões são representações simbólicas das vivências da humanidade. Deste modo, não se desconsidera a amplitude da obra de Eliade, mas apresenta-se apenas a similaridade do pensamento desses autores.
} 
para a cultura do Oriente, já que no primeiro prevalecem os aspectos racionais, a atitude extrovertida e patriarcal; e, no segundo, a atitude irracional, introvertida e matriarcal. Ao identificar diferenças e confronto entre Oriente e Ocidente, Zimmer propõe, como os demais autores em Eranos, a volta do irracional-matriarcal por meio da atitude interior ${ }^{6}$. Desta forma, o Ocidente poderá, resguardando suas particularidades, aproximar-se da cultura oriental, ao resgatar em si os símbolos que podem conduzir o homem ocidental ao processo de transformação, analogamente ao homem oriental.

O objetivo principal de Eranos sempre foi o de compensar a unilateralidade do racionalismo pela abordagem do simbólico. A sociedade acha-se em busca de confrontação e mediação do simbólico, de integração dos contrários, de uma discussão entre Oriente e Ocidente, mito e razão, diferença e identidade (Ortiz-Osés, 1994).

Para uma melhor compreensão deste simbólico em Eranos, na formação de seus adeptos, as palestras de C. Gustav Jung em sua origem até os anos 60 são fundamentais não somente para os pertencentes ao Círculo, mas também para o aprofundamento de suas obras na pertinência ao simbólico.

\section{O simbólico nas palestras de Eranos, a partir de Jung}

Por mais que Jung resistisse a ser o fundador de Eranos, suas pesquisas foram importantes por tratar de temas que confirmavam a proposta de Eranos, principalmente quando refletiam sobre a necessidade de diálogo entre 0 Ocidente e o Oriente, uma conjunção do simbólico-mítico (inconsciente) com o terminológico-científico (consciente). Esta conjunção dos opostos é o resultado do diálogo entre os princípios opostos, que em nossa cultura se negam mutuamente e permanecem separados (Ortiz-Osés, 1994).

Eranos propiciava a Jung a oportunidade de continuar suas pesquisas; era um lugar propício a temas que estavam fora do âmbito acadêmico daquela época. Deste modo, Jung já pesquisava temas com a mesma perspectiva de Eranos, em que a representação do simbólico-mítico estava presente. Dentre as obras de Jung, antes e durante Eranos, podem-se destacar textos importantes, como o livro Psicologia e alquimia (1945), que reúne diversos textos sobre o tema da alquimia.

Deste modo, Eranos foi importante para Jung, como também Jung o foi para Eranos. Segundo Bernardini (2011), se Jung forneceu uma demarcação psicológica a Eranos, este propiciou uma demarcação intelectual à teoria de Jung. Por meio do inconsciente coletivo e dos arquétipos

6 O trabalho de Zimmer não se restringe apenas à dimensão, à volta do irracional-matriarcal proposto em Eranos. É possível perceber a dimensão de seu trabalho no livro Filosofias da Índia (Zimmer, 1986), que descreve o encontro entre Ocidente e Oriente, apontando para as diferenças fundamentais entre ambos, e apresenta um estudo minucioso mítico-religioso do Oriente. Joseph Campbell o considerava o grande conhecedor do Oriente e afirmava que "ouvi-lo é como assistir a uma dança shankar. Trata-se de uma mitologia orquestrada" (Cousineau, 2003, p. 153). apresentados em Eranos, foi possível pensar em uma elaboração psicológica de toda uma reflexão filosófica e cultural.

Os mais diversos assuntos abordados por Jung em sua obra, que consolidaram suas pesquisas e conceitos como, inconsciente pessoal, coletivo, arquétipos, si-mesmo e individuação, igualmente estavam presentes nas conferências ministradas em Eranos. Foi fundamental para Jung dialogar com autores como Otto, Eliade e Zimmer; e desenvolver pesquisas voltadas à temática da religião e sobre as tradições religiosas do Ocidente-Oriente.

Logo, pode-se destacar que, ao se referir aos mitos, às religiões e, principalmente, à religião ocidental, Jung afirma que as experiências humanas giram em torno da numinosidade do arquétipo e, em especial, do arquétipo do si-mesmo. Deste modo, infere-se que as representações do si-mesmo por meio de figuras geométricas, da mandala e de figuras religiosas, como Cristo, estão presente nos mitos e nas religiões, sobremaneira na religião da tradição ocidental (Jung, 1988)?

Pode-se inferir ainda que o intuito de Jung em Eranos, ao considerar as representações religiosas como manifestações arquetípicas, era de estabelecer um diálogo entre a cultura ocidental e a oriental, uma vez que sua proposta consistia em integrar os opostos apartados pela atitude de racionalização e negação do irracional predominante na tradição ocidental. Destarte, Ortiz-Osés (1994) aponta que

Neste sentido, podemos considerar que o que Jung fez ao tecer sua linguagem foi colocar em prática sua própria teoria da necessidade de um diálogo frutífero entre o matriarcal-inconsciente (oriental) e o patriarcal-racionalista (ocidental). Certamente, isso implica uma crítica radical da mentalidade ocidental dominante, como se faz patente quando afirma que atrás da fragância do Oriente, vem o homem europeu, desagradável, ladrão de almas, conquistador, representante da "religião do amor", comerciante de ópio, desorientado, miserável apesar da abundância de sua sabedoria e de sua arrogância intelectual. Essa é a imagem do homem ocidental. Contudo, esta autocrítica do europeu cristão não se resolve com uma proposta de imitação, conversão ou fuga para o Oriente, com uma apologética do exótico, pois que o matriarcal-inconsciente, por mais que no Oriente seja predominante, encontra-se no fundo autóctone de nossa própria cultura, no fundo de cada um. Para encontrá-lo não é preciso, dessa forma, ir muito longe; mas com sua localização não se fez mais que iniciar a aventura decisiva, a confrontação mutuamente transformadora. Tratase, com efeito, de uma transformação recíproca do

\footnotetext{
7 Referente à numinosidade do arquétipo e do símbolo do si-mesmo podem ser pesquisado nos livros Psicologia da religião ocidental e oriental. (Jung, 1988); e AION, estudos sobre o simbolismo do si-mesmo. (Jung,1986).
} 
inconsciente ou da consciência pela sua conjugação ou pelo contato. (p. 44, N.T)

O mérito de Jung foi "diagnosticar" em nossa cultura greco-cristã a separação do simbólico-mitológico, do científico. Segundo Ortiz-Osés (1994),

Nossa cultura ocidental mostra-se, desse modo, ambivalentemente caracterizada, por um lado, pela realização (positiva) dessa separação ou emancipação e, por outro lado, pela detenção ou fixação (negativa) na mesma que acarreta uma custosa repressão do fator inconsciente e uma perigosa inflação do fator consciente, em virtude da qual o eu, esquecendo-se de onde vem, reclama-se como ponto central da psique. (p. 44, N.T)

Ao identificar uma repressão do inconsciente e uma inflação consciente na cultura greco-cristã, Jung relata que é necessária para nossa sociedade a criação de uma nova forma para expressar e simbolizar seu potencial simbólico-mítico. Assim, ele propõe um diálogo entre a atitude matriarcal-inconsciente (oriental) e a patriarcal-racionalista (ocidental). Jung sugere que, para encontrar seu potencial simbólicomítico, o Ocidente não tem que imitar a cultura do Oriente (hinduísmo), mas sim apresentar uma atitude decisiva, uma confrontação mutuamente transformadora, qual seja, uma confrontação e valorização tanto dos aspectos conscientes quanto dos inconscientes, para que ocorra a transformação. Neste mesmo caminho Ortiz-Osés (1994) relata

Que a conjugação possa ser uma mútua transformação, implica que a façamos com realidades relacionais ou correlativas; o modo como o inconsciente se apresenta à atitude com que a consciência o aborde e, vice-versa, o modo consciência está em função do modo no qual o inconsciente se faz constar. Assim, pois, a linguagem que Jung fornece a Eranos está gestada em sua própria experiência profissional e de vida, na aventura de sua alma que, incapaz de encontrar refúgio na tipicidade de nossa cultura patriarcal, sentindo-se estrangeiro no terreno baldio do presente, transgrediu seus limites, mergulhou em suas próprias profundezas, tocando fundo e tendo a sorte de encontrar um caminho de volta. (p. 44, N.T)

Com o objetivo de compreender a simbolização do ser humano no campo da vivência, Jung propõe, em sua Psicologia Complexa ou Psicologia Analítica na apresentação de Eranos, pensar um modelo que viesse a focar a alma humana numa tentativa de diálogo interdisciplinar, o qual se diferenciasse da escola psicoterapêutica freudiana, e que indicasse uma estrutura arquetípica como pano de fundo do fenômeno religioso. A contribuição de Jung em Eranos dar-se-ia no âmbito da psicologia, delineando a psicologia complexa segundo a qual a estrutura do fenômeno religioso derivaria das estruturas arquetípicas da alma. A hermenêutica de Eranos vem nos apresentar, no geral, uma visão de mundo, uma síntese, uma religiosidade, o arquétipo, o mito, o simbólico e a individuação (Bernardini, 2011).

Deste modo, pode-se concluir que o pensamento de Jung referente aos arquétipos ocorria anteriormente à criação do Eranos. Primeiramente foram as pesquisas de Jung referentes aos complexos ${ }^{8}$ e seus aspectos inconscientes, que num primeiro momento lhe proporcionaram uma aproximação de sua teoria dos complexos da estrutura do inconsciente proposta por Freud; todavia, após o desenvolvimento de sua pesquisa e observação clínica de pacientes psicóticos, elementos estruturais que iam além da proposta freudiana foram reconhecidos. Jung identificou conteúdos arcaicos de caráter mitológico não condizentes com as experiências pessoais dos pacientes, o que levou a uma reformulação de sua teoria e, consequentemente, a divergências e posterior ruptura com Freud (Boechat, 2004).

Desta maneira, pode-se apontar que uma das divergências mais incisivas entre esses dois autores deu-se quanto ao entendimento do inconsciente. Enquanto para Freud o inconsciente era constituído por conteúdos de caráter pessoal, reprimidos e recalcados, para Jung o inconsciente seria tanto pessoal quanto coletivo, sendo o primeiro semelhante ao modelo freudiano e o segundo, de natureza coletiva, envolvendo características comuns a toda a humanidade. Seria "um inconsciente coletivo constituído das formas primitivas típicas de vivências e comportamentos da espécie humana", isto é, "pura e simplesmente da possibilidade herdada de um funcionamento psíquico" (Jacobi, 1990, p. 27).

Na busca de explicitar as características do inconsciente, Jung (2000) escreve que

Uma das camadas mais ou menos superficial do inconsciente é indubitavelmente pessoal. Nós a denominamos inconsciente pessoal. Este, porém, repousa sobre uma camada mais profunda, que já não tem sua origem em experiência ou aquisições pessoais, sendo inata. Esta camada mais profunda é o que chamamos inconsciente coletivo. (p. 15)

Assim, para Jung (2000), "enquanto o inconsciente pessoal consiste em sua maior parte de complexos, o conteúdo do inconsciente coletivo é constituído essencialmente de arquétipos" (p. 53). Para ele, o inconsciente coletivo abrange toda a humanidade e deriva das imagens primordiais referentes a experiências psíquicas ancestrais, as quais ele denominou arquétipos. "Essas 'imagens primordiais' ou 'arquétipos', como eu os chamei, pertencem

\footnotetext{
8 Segundo Jacobi (1990) "Freud vê o complexo apenas a partir do doente, Jung, a partir do sadio" (p. 28); ou seja, para Freud os complexos têm caráter negativo, resultado do mecanismo de repressão; já para Jung os complexos podem possuir características patológicas, mas também possuem aspecto positivo e teleológico (prospectivo). "Trata-se, então, para Jung, de um aspecto duplo do mesmo complexo, que, sem deixar de levar em conta o aspecto freudiano, acrescenta, no entanto, a ele, outro aspecto a mais" (p. 29).
} 
ao substrato fundamental da psique inconsciente e não podem ser explicados como aquisições pessoais. Todos juntos formam aquele extrato psíquico ao qual dei o nome de inconsciente coletivo" (Jung, 1984, pp. 115-116).

Jung (2000) dá um passo importante quando se dedica à consideração mais precisa dos conteúdos do inconsciente coletivo, percebendo que os arquétipos se manifestam em diversas culturas. Deste modo, ele não tenta provar a existência do inconsciente coletivo, mas propõe a sua existência como parte de sua hipótese operacional destinada a explicar o paralelismo quase universal de certas imagens culturais, o qual se manifesta por meio de diversas experiências psicológicas, como temas míticos, vivências religiosas, sonhos e casos clínicos de pacientes.

Para o psicólogo suíço, os arquétipos consistiriam nas formas pré-existentes que estão presentes na psique da humanidade, experiências que, por se repetirem desde os tempos mais remotos, acabaram dando origem aos arquétipos. "Os arquétipos são formas de apreensão e todas as vezes que nos deparamos com formas de apreensão que se repetem de maneira uniforme e regular, temos diante de nós um arquétipo" (Jung, 1984, p. 141).

Deste modo, pode-se observar que, já em 1912, quando escreve o texto "Símbolos da Transformação" (Jung, 2011) e também em 1919, quando publica o texto "Sobre os Arquétipos do Inconsciente Coletivo" (Jung, 2000), Jung já se referia aos arquétipos e atribuía características numinosas a estes. Portanto, a apropriação do conceito de numinoso ${ }^{9}$ por Jung foi marcante para a descrição das características arquetípicas da experiência humana, atribuindo destaque especial às experiências religiosas, pela evidência de seu aspecto numinoso, inconsciente e arquetípico.

Referindo-se aos arquétipos, Jung (1988) relata que possuem um efeito numinoso; segundo ele, "o arquétipo, onde quer que se manifeste, tem um caráter compulsivo, precisamente por proceder do inconsciente; quando seus efeitos se tornam conscientes, se caracteriza pelo aspecto numinoso" (p. 149). Assim como o numinoso descrito por Otto (2007), os arquétipos possuem características opostas e complementares, ou seja, o numinoso/arquetípico pode ser ao mesmo tempo aterrorizante e fascinante.

Identicamente à descrição de Otto, Jung enfatiza a dualidade e a complementaridade dos arquétipos. Óbvio que não se acha no inconsciente a questão da dualidade, pois que ela se processa pela consciência. É através da consciência que se pode saber o que é mal ou o que é bem, o que é luz e o que é treva. Nesta trilha Jung (1986) descreve que

A Psicologia sabe que os opostos correlatos constituem condições imprescindíveis e inerentes ao ato do conhecimento, pois sem eles seria impossível qualquer tipo de diferenciação. Mas é muito

9 Referente à característica numinosa do arquétipo, observar-se-á posteriormente que Jung se apropria do conceito de numinoso de Otto, fato este que irá consolidar em Eranos o diálogo entre Jung e outros autores. pouco provável que aquilo que está tão ligado ao ato de conhecimento seja "o ipso" [automaticamente], também uma qualidade do objeto. Muito pelo contrário, podemos pensar que é sobretudo nossa consciência que designa as diferenças das coisas, as avalia e produz, inclusive onde é impossível apreender quaisquer diferenças. (p. 57)

Sendo assim, entende-se que pela consciência diferenciam-se as características dos opostos, quer dizer, "a síntese entre os conteúdos conscientes e inconscientes e a tomada de consciência dos efeitos dos arquétipos sobre os conteúdos conscientes representam o ponto máximo do esforço espiritual e da concentração das forças psíquicas" (Jung, 1984, pp. 215-216). Assim, "os opostos se condicionam reciprocamente e, no fundo, constituem uma só e a mesma coisa" (Jung, 1988, p. 50).

Sobre dualidade e complementaridade, Jung descreve que todos os arquétipos possuem efeito numinoso, mas só um possui o caráter de ordenar e equilibrar o confronto dos opostos, conteúdos conscientes e inconscientes. Nesta linha de raciocínio, ele ressalva:

Como, porém o si-mesmo psicológico é um conceito transcendente, pelo fato de exprimir a soma dos conteúdos conscientes e inconscientes, ele só pode ser descrito sob a forma de uma antinomia, isto é, os atributos acima mencionados devem ser completados por seus respectivos contrários, para que possam caracterizar devidamente o fato transcendental. (Jung, 1986, p. 58)

Jung (1986) compreende o si-mesmo como a totalidade psíquica, o qual representa o âmbito de todos os fenômenos psíquicos, abrangendo o lado consciente e inconsciente da psique humana. Jung define o si-mesmo (self) como uma grandeza que transcende o eu e, ao mesmo tempo, o inclui. O eu é o centro da consciência e o si-mesmo, o centro e a totalidade da esfera psíquica.

O termo "si-mesmo" parece adequado para designar esse pano de fundo inconsciente, cujo expoente na consciência de cada indivíduo é o eu. O eu está para "si-mesmo" assim como o "patiens" está para o "agens", ou como o objeto está para o sujeito, porque as disposições que emanam do si-mesmo são bastante amplas e, por isso mesmo, superiores ao eu. Da mesma forma que o inconsciente, o si-mesmo é o existente a priori do qual provém o eu. É ele que, por assim dizer, predetermina o eu. Não sou eu que me crio; mas sou eu que aconteço a mim mesmo. (Jung, 1988, pp. 262-263)

Segundo Stein (2006), o conceito de si-mesmo ou self, na visão de Jung, é transcendente, não é definido pelo domínio psíquico nem está contido nele, está além dele, ou seja, o si-mesmo é mais que a subjetividade da pessoa. 
Esta característica transcendente é atribuída a todos os arquétipos, mas o arquétipo do si-mesmo é enfatizado por Jung (1986) em especial, por referir-se ao arquétipo da totalidade.

Segundo Jung (1994) o si-mesmo representa o âmbito de todos os fenômenos psíquicos do homem, abrangendo o lado consciente e inconsciente da psique humana. Ele é o arquétipo da totalidade que contém o princípio da união dos opostos, unium oposittorim, que permite ao ego passar a uma nova consciência, uma característica transcendente. A este processo no qual o simesmo passa do estado de dissolução no inconsciente para um estágio consciente, ele nomeia processo de individuaçã $0^{10}$. Referente ao processo de individuação, Jung (1988) acrescenta

Mas, para que se tome consciência do processo de individuação, é preciso que a consciência seja confrontada com o inconsciente e se chegue a um equilíbrio dos opostos. Como isto é logicamente impossível, necessita-se de símbolos que sirvam para tornar visível a união irracional dos contrários. Estes símbolos são produzidos espontaneamente pelo inconsciente e ampliados pela consciência. Os símbolos centrais deste processo descrevem o si-mesmo, i.é, a totalidade do homem, de um lado, por meio daquilo que lhe é consciente e, de outro, por meio do conteúdo inconsciente. (p. 470)

Segundo Jung, o próprio inconsciente cria os símbolos para que ocorra um equilíbrio dos opostos. Em outras palavras, no confronto entre os opostos (consciente e inconsciente), faz-se necessário que um equilíbrio decorra a fim de que a psique tome consciência dos conteúdos obscuros e assim, atinja o processo de individuação. Neste sentido, Jung (1988) sustenta que, "qualquer que seja o significado da totalidade, do simesmo do homem, trata-se empiricamente de uma imagem de finalidade da vida, produzida espontaneamente pelo inconsciente, para além dos desejos e temores da consciência" (p. 462).

Portanto, "psicologicamente falando, o si-mesmo foi definido como a totalidade psíquica do homem. Tudo aquilo que o homem supõe constituir, de per si, uma totalidade mais ampla, pode tornar-se símbolo do Si-mesmo" (Jung, 1988, p. 156). Nesta mesma ordem Jung (1988) revela que

o Si-mesmo não é apenas um conceito abstrato, ou um postulado lógico, mas uma realidade psíquica que só é consciente até certo ponto, abrangendo também a vida do inconsciente, razão pela qual não

10 Individuação é processo de auto-realização ou desenvolvimento; como na evolução biológica, ocorre também na evolução psicológica (Jung, 1988). é diretamente perceptível à observação, só podendo exprimir-se em símbolos. (p. 157)

Deste modo, nesta mesma perspectiva, Jung discorre sobre a psique humana, identificando, nos diversos mitos, culturas e religiões que também apresentam esse confronto de opostos, o mesmo que permite criar símbolos como forma de expressão e equilíbrio. Percebe-se, pois, que o entendimento de Jung, que se refere ao funcionamento psíquico do ser humano, ele o estende a todas as experiências humanas vividas, as quais constituem as diversas religiões e mitos.

Em Eranos, a psicologia junguiana pode reafirmar os princípios científicos e os estudos do simbólico, mitológico e religioso, de épocas passadas e também da atual." A partir disso, traça um paralelismo entre esses elementos e o processo psicológico de individuação, entendido como o reconhecimento da dimensão pessoal imersa em uma dimensão coletiva muito mais ampla, o que acarreta a formação de uma consciência estendida, oriunda tanto de processos individuais quanto de coletivos (Bernardini, 2011).

\section{Considerações finais}

Entender a importância do simbólico em Eranos, na tentativa de compreender o Oriente e o Ocidente, abre caminho para que Jung e tantos outros autores participantes deste Círculo defendam a necessidade de uma busca da essência humana no campo da cultura.

O Círculo de Eranos continua a oferecer essa mediação entre o reino da consciência e do inconsciente, do espírito e da razão, do anímico e do racional, do eu e do si mesmo que levou Ortiz-Osés (2004) a entendê-lo como um círculo hermenêutico compreensivo baseado na interpretação, e que o simbólico deve ser uma prática de investigação interdisciplinar para compreender o homem em suas dimensões.

O diálogo entre a Cultura Oriental (inconsciente matriarcal - irracional) e a Ocidental (consciente - patriarcal - racional) representa a proposta geral de Eranos, em que tanto Ocidente quanto Oriente possam voltar ao diálogo mútuo, principalmente contrapondo o espírito racionalista e positivista caracterizado no começo do século XX e que abre caminhos para entender de forma interdisciplinar o simbólico em diversos autores, dentre os quais Jung se destaca.

Jung apresenta uma perspectiva que vai em direção à valorização dos aspectos simbólicos, arquetípicos e mitológicos da cultura e do ser humano, ou seja, dos aspectos a-histórico e arcaico da humanidade (Eranos Foundation, n.d.).

Estes aspectos apontam para o simbólico no indivíduo de tal maneira que, ao tentar compreender autores que

11 Jung já estava realizando pesquisas para o estudo do simbólico, do mitológico e do religioso, entendendo que estes seriam representações da vivência humana, ou seja, experiências primordiais da humanidade, as quais ele denominou, em 1919, arquétipos (Jung, 2000). 
participaram do Círculo de Eranos, e que desenvolveram suas pesquisas, estabeleceu-se a necessidade de olhares diferentes para a interpretação da cultura no que remonta à construção imaginária do real. Ao apresentar Jung e sua relação com o Círculo de Eranos, compreende-se melhor sua obra, já além de seu tempo; compreende-se melhor, também, a obra de autores que participaram deste Círculo, de forma interdisciplinar.

Em Eranos foi possível um retorno ao simbólicomítico, elemento este que potencializa o fato de que os pesquisadores foram influenciados por uma tendência de estudo do simbolismo no qual se buscava um conhecimento gnóstico, o qual se explicitava por uma tentativa de captação - não do sentido racional e objetivo das experiências - mas do nível mais profundo das experiências vividas, tendo o mito como forma privilegiada de expressão.

Eranos proporcionou aos estudiosos uma concepção do simbólico que permitisse a integração dos contrários, Ocidente-Oriente, do racional-patriarcal com irracional -matriarcal, cujo objetivo era compensar a unilateralidade do racionalismo pela abordagem do simbólico. O simbólico, assim, assume uma nova conotação na sociedade, e muitos autores passam a identificá-lo como fator essencial na constituição das culturas e do ser humano.

Ressaltou-se, pois, em Jung - um dos principais expoentes e também fundador de Eranos - a relevância do simbólico e, na constituição do ser humano, uma arquetipologia simbólica cuja meta se envereda pelo complexio oppositorum (complexos opostos), uma união dos opostos.

Jung desvelou em Eranos uma perspectiva que focasse no estudo da alma humana e que indicasse uma estrutura arquetípica como pano de fundo do fenômeno religioso, segundo o qual, a estrutura do fenômeno religioso derivaria das estruturas arquetípicas da alma. Deste modo, os mitos e o fenômeno religioso passam a ser imprescindíveis para a compreensão do ser humano.

Assim é que a Psicologia de Jung se torna essencial ao Círculo de Eranos, suas pesquisas e o entendimento que tinha do ser humano vieram a se tornar fundamentais para a compreensão de mundo, uma vez que, anteriormente, valorizavam-se os aspectos racionais vislumbrados pelo ser humano e pela cultura - principalmente pela ocidental - descaracterizando-se a importância do simbólico. A hermenêutica de Eranos vem, em decorrência, nos apresentar uma visão de mundo em geral; uma síntese, uma religiosidade: o arquétipo, o mito, o simbólico e a individuação como possibilidade de integração dos opostos, ou seja, unium oppositorum do Ocidente-Oriente, racional-irracional.

\section{From Eranos Circle to the symbolic construction in Carl Gustav Jung}

Abstract: The article discusses the origin and extent of the Eranos Circle and its importance in understanding the symbolic, establishing the comprehension of the symbolic construction as an attempt to unite East and West in C. G. Jung.

Keywords: Eranos, symbolic, archetype, Jung.

\section{Du Cercle d'Eranos à la construction du symbolique chez Carl Gustav Jung}

Résumé: Cet article discute l'origine et l'extension du Cercle d'Eranos, et son importance pour la compréhension du symbolique. Ce travail vise à établir une compréhension de la construction du symbolique comme une tentative de l'union de l'Orient et I'Occident dans la pensée de C. G. Jung.

Mots-clés: Eranos, archétype, symbolique, Jung.

\section{Del Círculo de Eranos a la construcción del simbólico, en Carl Gustav Jung}

Resumen: Este artículo discute el origen y la extensión del Círculo de Eranos, así como su importancia para la comprensión del simbólico. Su objetivo es establecer la comprensión de la construcción del simbólico como tentativa de unión entre Oriente y Occidente en C. G. Jung.

Palabras clave: Eranos, simbólico, arquetipo, Jung. 


\section{Referências}

Araújo, A. F., \& Baptista, F. P. (2003). Variações sobre o imaginário: domínios, teorizações, práticas hermenêuticas. Lisboa, Portugal: Instituto Piaget.

Barreto, M. H. (2008). Imaginação simbólica. São Paulo, SP: Loyola.

Bernardini, R. (2011). Jung a Eranos: Il progetto della psicologia complessa. Milano, Italy: Franco Angeli s.r.1.

Boechat, W. (2004). O corpo psicóide: a crise de paradigma e o problema da relação corpo-mente (Tese de doutorado). Universidade Federal do Rio de Janeiro, IMS, Rio de Janeiro.

Campbel, J. (1986). Filosofias da Índia. São Paulo, SP: Palas Athena.

Carvalho, J. C. P. (1998). Imaginário e mitodologia: Hermenêutica dos símbolos e estórias da vida. Londrina, PR: UEL.

Cassirer, E. (1994). Ensaio sobre o homem. Introdução a uma filosofia da cultura humana. São Paulo, SP: Martins Fontes.

Cavalcanti, T. R. A. (1998). A psicologia da religião de Carl Gustav Jung e a abordagem religiosa de Mircea Eliade: acertos e desacertos de uma leitura psicológica dos símbolos religiosos (Dissertação de Mestrado). Pontifícia Universidade Católica de São Paulo, São Paulo.

Cousineau, P. (2003). A jornada do herói - Joseph Campbell - vida e obra. São Paulo, SP: Àgora.

Eranos Foundation. (n.d.). Who we are: History and meaning of Eranos. Recuperado de http://www.eranosfoundation. org/history.htm

Jacobi, J. (1990). Complexo, arquétipo e símbolo na psicologia de C. G. Jung. São Paulo, SP: Cultrix.

Jung, C. G. (1984). A dinâmica do inconsciente. Petrópolis, RJ: Vozes.
Jung, C. G. (1986). AION estudos sobre o simbolismo do simesmo. Petrópolis, RJ: Vozes.

Jung, C. G. (1988). Psicologia da religião ocidental e oriental. Petrópolis, RJ: Vozes.

Jung, C. G. (1994). Psicologia e alquimia. Petrópolis, RJ: Vozes.

Jung, C. G. (2000). Os arquétipos e o inconsciente coletivo. Petrópolis, RJ: Vozes.

Jung. C. G. (2011). Símbolos da transformação. Petrópolis, RJ: Vozes.

Mackenna, C. (2009). From the numinous to the sacred. Journal of Analytical Psychology, 54, 167-182.

Mattos, S. M. (2013). Simbolismo do herói - uma abordagem sobre a Ciência do Imaginário. Curitiba, PR: CRV.

Ortiz-Osés, A. (Org.). (1994). El Círculo de Eranos: uma hermenêutica simbólica del sentido. Anthropos: Revista de Documentación Cientifica de la Cultura, (153).

Ortiz-Osés, A. (2004). Arquetipos y simbolos colectivos. Circulo de Eranos I (Cuadernos de Eranos- Cahiers d' Eranos). México: Antropos Editorial-Centro Regional de Investigações Multidisciplinares.

Otto, R. (2007). O sagrado: os aspectos irracionais na noção do divino e sua relação do divino e sua relação com o irracional. Petrópolis, RJ: Vozes.

Santomé, J. T.(1998). Globalização e interdisciplinaridade. Porto Alegre, RS: Artmed.

Stein, M. (2006). O mapa da alma. São Paulo, SP: Cultrix.

Zimmer, H. (1986). Filosofias da Índia. São Paulo, SP: Palas Athena. 